\title{
Outbreak of staphylococcal food poisoning among children and staff at a Swiss boarding school due to soft cheese made from raw milk
}

\author{
Sophia Johler, ${ }^{* 1}$ Delphine Weder, $\uparrow$ Claude Bridy, $\dagger$ Marie-Claude Huguenin, $\dagger$ Luce Robert, $\dagger$ \\ Jörg Hummerjohann, $\ddagger$ and Roger Stephan* \\ *Institute for Food Safety and Hygiene, Vetsuisse Faculty, University of Zurich, 8057 Zurich, Switzerland \\ †Service de la Consommation et des Affaires Vétérinaires, Département du Développement Territorial et de l'Environnement République \\ et Canton de Neuchâtel, 2001 Neuchâtel, Switzerland \\ $\ddagger$ Agroscope, Institute for Food Sciences, 3003 Bern, Switzerland
}

\section{ABSTRACT}

On October 1, 2014, children and staff members at a Swiss boarding school consumed Tomme, a soft cheese produced from raw cow milk. Within the following $7 \mathrm{~h}$, all 14 persons who ingested the cheese fell ill, including 10 children and 4 staff members. Symptoms included abdominal pain and violent vomiting, followed by severe diarrhea and fever. We aim to present this food poisoning outbreak and characterize the causative agent. The duration of the incubation period was dependent of the age of the patient: $2.5 \mathrm{~h}$ in children under $10 \mathrm{yr}$ of age, $3.5 \mathrm{~h}$ in older children and teenagers, and $7 \mathrm{~h}$ in adults. The soft cheese exhibited low levels of staphylococcal enterotoxin (SE) A ( $>6 \mathrm{ng}$ of SEA/g of cheese) and high levels of staphylococcal enterotoxin D (>200 ng of $\mathrm{SED} / \mathrm{g}$ of cheese). Counts of $10^{7} \mathrm{cfu}$ of coagulase-positive staphylococci per gram of cheese were detected, with 3 different Staphylococcus aureus strains being present at levels $>10^{6} \mathrm{cfu} / \mathrm{g}$. The 3 strains were characterized using spa typing and a DNA microarray. An enterotoxinproducing strain exhibiting sea and sed was identified as the source of the outbreak. The strain was assigned to spa type t711 and clonal complex 8, and it exhibited genetic criteria consistent with the characteristics of a genotype B strain. This genotype comprises bovine Staph. aureus strains exclusively associated with very high within-herd prevalence of mastitis and has been described as a major contaminant in Swiss raw milk cheese. It is therefore highly likely that the raw milk used for Tomme production was heavily contaminated with Staph. aureus and that levels further increased due to growth of the organism and physical concentration effects during the cheese-making process. Only a few staphylococcal food poisoning outbreaks involving

Received November 18, 2014

Accepted January 14, 2015.

${ }^{1}$ Corresponding author: sophia.johler@uzh.ch raw milk products have been described. Still, in view of this outbreak and the possible occurrence of other foodborne pathogens in bovine milk, consumption of raw milk and soft cheese produced from raw milk constitutes a health risk, particularly when young children or other members of sensitive populations are involved. Key words: outbreak investigation, Staphylococcus aureus, raw milk cheese, genotype B

\section{INTRODUCTION}

Staphylococcal food poisoning (SFP) is one of the most prevalent causes of foodborne intoxication worldwide, resulting in an estimated 241,148 cases and 6 deaths in 2006 in the United States alone (Scallan et al., 2011). After a short incubation period of 2 to $6 \mathrm{~h}$, patients exhibit nausea, followed by violent vomiting and diarrhea (Tranter, 1990). As clinical symptoms are typically self-limiting, it is estimated that only $10 \%$ of SFP patients visit a hospital (Holmberg and Blake, 1984). Consequences include pronounced underreporting of the disease and scarce scientific data on the characteristics of Staph. aureus strains causing SFP.

Staphylococcal food poisoning is caused by consumption of staphylococcal enterotoxins (SE) formed by Staph. aureus in food. To date, more than 20 different SE and SE-like superantigens have been described (Hennekinne et al., 2012), but only a few have been demonstrated to elicit an emetic response in a monkey feeding assay. Staphylococcal enterotoxins that have been shown to exhibit emetic activity include the classical enterotoxins SEA, SEB, SEC, SED, and SEE, and, to a limited degree, some newly described enterotoxins (Thomas et al., 2007).

In SFP outbreak investigations, identification of the causative strain can be challenging, as SE are highly heat resistant. Even when the organism is inactivated and can no longer be isolated from a food item, the highly stable enterotoxins formed by Staph. aureus can still cause SFP (Le Loir et al., 2003). In addition, 
identification of the causative strain in an outbreak investigation is aggravated by the high prevalence of Staph. aureus in humans and animals. Staphylococcus aureus persistently colonizes the anterior nares of 20 to $30 \%$ of the human population (van Belkum et al., 2009), causes a multitude of infections in humans and livestock, and can be isolated from a wide range of food items (Baumgartner et al., 2014). The organism also represents a common cause of bovine mastitis and can be detected in bulk tank milk at prevalence rates of 27 to $42 \%$ (Oliver et al., 2009).

On October 1, 2014, children and staff members at a Swiss boarding school consumed Tomme, a soft cheese produced from raw milk. Within $7 \mathrm{~h}$, all 14 persons who had consumed the cheese fell ill, among them 10 children and 4 members of the staff. Based on the short incubation time, as well as the clinical symptoms, SFP due to consumption of the raw milk cheese was considered a possible cause of the outbreak.

\section{MATERIALS AND METHODS}

\section{Enumeration and Isolation of Coagulase-Positive Staphylococci, Cell Lysis, and DNA Extraction}

Coagulase-positive staphylococci (CPS) present in the Tomme soft cheese (that had been stored at $4^{\circ} \mathrm{C}$ ) were enumerated according to EN ISO 6888-2 (ISO, 1999).

Different morphologies of colonies forming an opaque fibrin halo on rabbit plasma fibrinogen agar (Oxoid, Basel, Switzerland) after $48 \mathrm{~h}$ of incubation at $37^{\circ} \mathrm{C}$ were subcultured on $5 \%$ sheep blood agar (Oxoid) and incubated overnight at $37^{\circ} \mathrm{C}$. DNA was extracted using the DNeasy Blood and Tissue Kit (Qiagen, Hilden, Germany) and following the manufacturer's instructions.

\section{spa Typing}

The polymorphic $\mathrm{X}$ region of the spa gene was determined as previously described (Wattinger et al., 2012). Briefly, spa was amplified using spa-1113f (5'-TAA AGA CGA TCC TTC GGT GAG C-3') and spa-1514r primers (5'-CAG CAG TAG TGC CGT TTG CTT$3^{\prime}$ ) (Aires-de-Sousa et al., 2006) and the GoTaq PCR system (Promega AG, Dübendorf, Switzerland) at the following reaction conditions: (1) $5 \mathrm{~min}$ at $94^{\circ} \mathrm{C}$; (2) 35 cycles of $45 \mathrm{~s}$ at $94^{\circ} \mathrm{C}, 45 \mathrm{~s}$ at $60^{\circ} \mathrm{C}$, and $90 \mathrm{~s}$ at $72^{\circ} \mathrm{C}$; and (3) $10 \mathrm{~min}$ at $72^{\circ} \mathrm{C}$. The PCR amplicons were purified using the MinElute PCR Purification Kit (Qiagen). Sequencing was outsourced (Microsynth, Balgach, Switzerland) and spa types were determined using the $s p a$-server (http://spa.ridom.de/; Harmsen et al., 2003).

\section{Microarray-Based Genotyping}

The Staph. aureus Genotyping Kit 2.0 (Alere Technologies GmbH, Jena, Germany) was used to further characterize the Staph. aureus strains. This analytical tool can be used to predict clonal complex (CC) assignment (Monecke et al., 2008) and to determine the presence or absence of over 300 resistance and virulence genes, including genes encoding the major SE (sea-see), newly described SE (seg, seh, sei, sej, sek, sel, seq, ser), and enterotoxin-like superantigens ( selm, seln, selo, selu).

\section{Detection of SE in Cheese}

To screen for all major SE, an extract of the cheese sample was prepared and analyzed using SET2 miniVIDAS (bioMérieux, Lyon, France) according to the manufacturer's recommendations. The SET-RPLA (staphylococcal enterotoxin-reversed passive latex agglutination) kit (Oxoid) was subsequently used to enable semiquantitative detection of SEA, SEB, SEC, and SED.

\section{RESULTS AND DISCUSSION}

All persons who consumed the raw milk cheese fell ill, among them 10 children and 4 members of the staff (Table 1). Although the average incubation time was $4.4 \mathrm{~h}$, the individual duration of the incubation period depended on the age of the patient. Only $2.5 \mathrm{~h}$ after consumption of the cheese, the 2 youngest children (age 8 and 9 yr) complained about abdominal pain, fever, and aching limbs that progressed quickly to emesis, followed by severe diarrhea, and fever. One hour later, the older children (10-16 yr) exhibited the same symptoms, followed $3.5 \mathrm{~h}$ later by the adults $(31-57 \mathrm{yr})$. One person sought medical care and was treated.

We detected $10^{7}$ cfu presumptive CPS per gram of cheese in the Tomme sample. Different morphologies of coagulase-positive colonies exhibiting a phenotype consistent with Staph. aureus were visible on RPF agar (Figure 1), indicating contamination of the product with more than one Staph. aureus strain. Using SET2 miniVIDAS to screen for major SE, the cheese tested positive for SEA, SEB, SEC, SED, and SEE in $25 \mathrm{~g}$ of product. Subsequently, the SET-RPLA kit was used for semiquantitative detection of SEA, SEB, SEC, and SED, identifying low levels of SEA ( $>6 \mathrm{ng}$ of SEA $/ \mathrm{g}$ of cheese) and high levels of SED (>200 ng of SED/g of cheese) in the Tomme soft cheese. Staphylococcal enterotoxin $\mathrm{A}$ is the most common $\mathrm{SE}$ recovered from food-poisoning outbreaks (78\%) and is reported to cause symptoms of intoxication in humans at a total dose of 
Table 1. Overview of 10 children and 4 staff members who suffered from clinical signs of staphylococcal intoxication ${ }^{1}$

\begin{tabular}{lllcl}
\hline Patient & Sex & Age (yr) & $\begin{array}{c}\text { Incubation } \\
\text { time }(\mathrm{h})\end{array}$ & Symptoms \\
\hline 1 & $\mathrm{M}$ & 8 & 2.5 & Abdominal pain, emesis, diarrhea, fever \\
2 & $\mathrm{M}$ & 9 & 2.5 & Abdominal pain, emesis, diarrhea, fever \\
3 & $\mathrm{M}$ & 10 & 3.5 & Abdominal pain, emesis, diarrhea, fever \\
4 & $\mathrm{M}$ & 13 & 3.5 & Abdominal pain, emesis, diarrhea, fever \\
5 & $\mathrm{M}$ & 13 & 3.5 & Abdominal pain, emesis, diarrhea, fever \\
6 & $\mathrm{M}$ & 14 & 3.5 & Abdominal pain, emesis, diarrhea, fever \\
7 & $\mathrm{M}$ & 15 & 3.5 & Abdominal pain, emesis, diarrhea, fever \\
8 & $\mathrm{~F}$ & 15 & 3.5 & Abdominal pain, emesis, diarrhea, fever \\
9 & $\mathrm{~F}$ & 15 & 3.5 & Abdominal pain, emesis, diarrhea, fever \\
10 & $\mathrm{M}$ & 16 & 3.5 & Abdominal pain, emesis, diarrhea, fever \\
11 & $\mathrm{M}$ & 31 & 7 & Abdominal pain, emesis, bloody diarrhea, fever \\
12 & $\mathrm{M}$ & 33 & 7 & Abdominal pain, emesis, diarrhea, fever \\
13 & $\mathrm{M}$ & 41 & 7 & Abdominal pain, emesis, diarrhea, fever \\
14 & $\mathrm{~F}$ & 57 & Abdominal pain, emesis, diarrhea, fever \\
\hline
\end{tabular}

${ }^{1}$ With an average incubation time of $4.4 \mathrm{~h}$, the onset of symptoms was earlier in children than in adults.

only $200 \mathrm{ng}$ of SEA (Balaban and Rasooly, 2000). In a monkey feeding assay, $25 \mu \mathrm{g}$ of SEA $/ \mathrm{kg}$ of BW induced emesis, and in the house musk shrew, the $50 \%$ emetic dose $\left(\mathrm{ED}_{50}\right)$ for peroral administration equaled $32 \mu \mathrm{g}$ of SEA/kg of BW (Hu and Nakane, 2014). Although SED represents the second most common SE and can be detected in $38 \%$ of SFP outbreaks (Balaban and Rasooly, 2000), there is no comparable data on the effect of SED after oral intake. However, intraperitoneal injection of a total dose of $40 \mu \mathrm{g}$ of SED was shown to have an emetic effect in the house musk shrew (Hu and Nakane, 2014).

Three different Staph. aureus strains (SA_1, SA_2, SA_3) were isolated from the cheese and were further characterized by spa typing (Wattinger et al., 2012; Table 2). All 3 strains were present in the cheese sample at levels higher than $10^{6} \mathrm{cfu} / \mathrm{g}$, with SA_1 occurring at the highest level. A DNA microarray analysis was used to identify the Staph. aureus isolate that produced the major SE previously detected and to generate a virulence and resistance gene profile of the strains. Major staphylococcal enterotoxin genes were only detected in SA_1, a strain that exhibited both sea and sed (Table 2). Strain SA_1 was assigned to CC8, a clonal complex frequently detected among strains isolated from humans, animals, and food products. Based on the enterotoxins SEA and SED detected by SET-RPLA and the enterotoxin genes sea and sed detected in the microarray, Staph. aureus strain SA_1 isolated from the Tomme raw milk cheese was identified as the source of the outbreak.

Strain SA_1 was assigned to spa type t711 and CC8. The spa type t711 is commonly detected among bovine mastitis isolates in Switzerland (Johler et al., 2011; Sakwinska et al., 2011) and has also been described in association with infections in humans, including methicillin-resistant Staph. aureus (MRSA) infections caused by the USA300 clone (Yabe et al., 2010). Although SA_1 exhibited genes involved in $\beta$-lactam resistance (blaZ, blaI, blaR), no genes conferring methicillin resistance were detected. Strain SA1 belongs to CC8, a clonal complex frequently linked to SFP outbreak strains and staphylococcal infections in humans and animals (Monecke et al., 2009; Wattinger et al., 2012; Resch et al., 2013). In Switzerland, 13 to $36 \%$ of the Staph. aureus isolated from bovine mastitis milk (Sakwinska et al., 2011; Moser et al., 2013) and $12 \%$ of the Staph. aureus isolated from ready-to-eat foods (Baumgartner et al., 2014) belong to CC8.

Strain SA_1 exhibits genetic criteria (sea, sed, sej, CC8) consistent with the characteristics of a genotype

Table 2. Characteristics of the 3 Staphylococcus aureus strains isolated from the Tomme soft cheese made of raw milk, including the presence of genes encoding staphylococcal enterotoxins (SE)

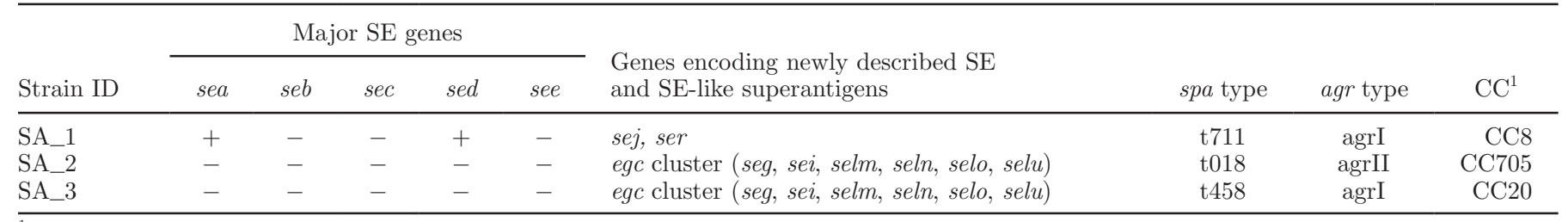

${ }^{1}$ Assignment to clonal complexes (CC) based on DNA microarray predictions. 


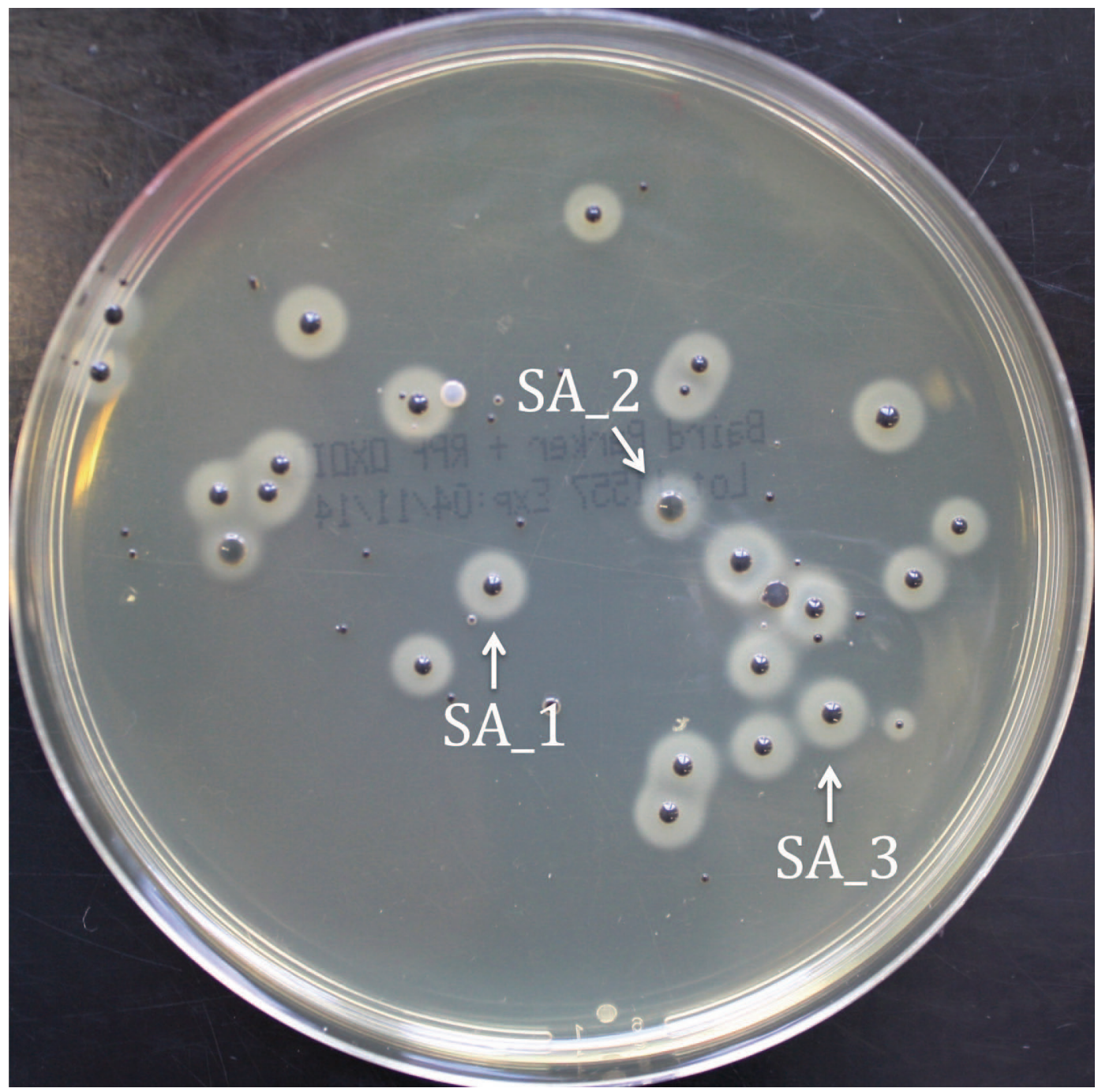

Figure 1. Rabbit plasma fibrinogen agar (RPF; Oxoid, Basingstoke, UK) used for enumeration of coagulase-positive staphylococci. Different morphologies of colonies consistent with a Staphylococcus aureus phenotype were visible on RPF (dilution 1:1,000,000), indicating contamination of the product with more than one Staph. aureus strain. The 3 phenotypes slightly differed in colony size, coloration, and the size of the fibrin reaction formed due to coagulase activity.

B strain (Boss et al., 2011; Moser et al., 2013). This genotype comprises bovine Staph. aureus strains exclusively associated with very high (up to $65 \%$ ) withinherd prevalence of mastitis (Graber et al., 2009) and has been described as a major contaminant in Swiss raw milk cheese (Hummerjohann et al., 2014). It is therefore highly likely that the raw milk used for Tomme production was strongly contaminated with Staph. aureus. Only a few SFP outbreaks involving raw milk products have been described and many are associated with goat or sheep milk products rather than products made of bovine raw milk (De Buyser et al., 2001; Giezendanner et al., 2009; Ostyn et al., 2010). During the production process of soft cheese made from raw milk, Staph. aureus levels can further increase due to both growth of the organism, as well as physical concentration effects that result in an estimated increase of $1 \log _{10}$ (Peng et al., 2013).

\section{CONCLUSIONS}

In view of this outbreak and the possible occurrence of other foodborne pathogens such as Shiga toxin-producing Escherichia coli in bovine milk, consumption of raw milk and soft cheese produced from raw milk constitutes a health risk, in particular when young children or members of other sensitive populations are involved. 


\section{ACKNOWLEDGMENTS}

This study was partially funded by a grant from the Swiss National Research Program 69 (40690_145211/1). We thank Henna-Maria Sihto (Institute for Food Safety and Hygiene, University of Zurich, Switzerland) for laboratory work.

\section{REFERENCES}

Aires-de-Sousa, M., K. Boye, H. de Lencastre, A. Deplano, M. C. Enright, J. Etienne, A. Friedrich, D. Harmsen, A. Holmes, X. W. Huijsdens, A. M. Kearns, A. Mellmann, H. Meugnier, J. K. Rasheed, E. Spalburg, B. Strommenger, M. J. Struelens, F. C. Tenover, J. Thomas, U. Vogel, H. Westh, J. Xu, and W. Witte. 2006. High interlaboratory reproducibility of DNA sequence-based typing of bacteria in a multicenter study. J. Clin. Microbiol. 44:619-621.

Balaban, N., and A. Rasooly. 2000. Staphylococcal enterotoxins. Int. J. Food Microbiol. 61:1-10.

Baumgartner, A., I. Niederhauser, and S. Johler. 2014. Virulence and resistance gene profiles of Staphylococcus aureus strains isolated from ready-to-eat foods. J. Food Prot. 77:1232-1236.

Boss, R., J. Naskova, A. Steiner, and H. U. Graber. 2011. Mastitis diagnostics: quantitative PCR for Staphylococcus aureus genotype B in bulk tank milk. J. Dairy Sci. 94:128-137.

De Buyser, M.-L., B. Dufour, M. Maire, and V. Lafarge. 2001. Implication of milk and milk products in food-borne diseases in France and in different industrialised countries. Int. J. Food Microbiol. 67:1-17.

Giezendanner, N., B. Meyer, M. Gort, P. Müller, and C. Zweifel. 2009. (Raw milk-associated Staphylococcus aureus intoxication in children). Schweiz. Arch. Tierheilkd. 151:329-331. [In German]

Graber, H. U., J. Naskova, E. Studer, T. Kaufmann, M. Kirchhofer, M. Brechbühl, W. Schaeren, A. Steiner, and C. Fournier. 2009. Mastitis-related subtypes of bovine Staphylococcus aureus are characterized by different clinical properties. J. Dairy Sci. 92:1442-1451.

Harmsen, D., H. Claus, W. Witte, J. Rothgänger, H. Claus, D. Turnwald, and U. Vogel. 2003. Typing of methicillin-resistant Staphylococcus aureus in a university hospital setting by using novel software for spa repeat determination and database management. J. Clin. Microbiol. 41:5442-5448

Hennekinne, J.-A., M.-L. De Buyser, and S. Dragacci. 2012. Staphylococcus aureus and its food poisoning toxins: Characterization and outbreak investigation. FEMS Microbiol. Rev. 36:815-836.

Holmberg, S. D., and P. A. Blake. 1984. Staphylococcal food poisoning in the United States. New facts and old misconceptions. JAMA 251:487-489.

Hu, D.-L., and A. Nakane. 2014. Mechanisms of staphylococcal enterotoxin-induced emesis. Eur. J. Pharmacol. 722:95-107.

Hummerjohann, J., J. Naskova, A. Baumgartner, and H. U. Graber. 2014. Enterotoxin-producing Staphylococcus aureus genotype B as a major contaminant in Swiss raw milk cheese. J. Dairy Sci. 97:1305-1312.

ISO. 1999. EN ISO 6888-2: Microbiology of food and animal feeding stuffs-Horizontal method for the enumeration of coagulase-positive staphylococci: Part 2: Technique using rabbit-plasma fibrinogen agar medium. International Organisation for Standardization (ISO), Geneva, Switzerland.
Johler, S., F. Layer, and R. Stephan. 2011. Comparison of virulence and antibiotic resistance genes of food poisoning outbreak isolates of Staphylococcus aureus with isolates obtained from bovine mastitis milk and pig carcasses. J. Food Prot. 74:1852-1859.

Le Loir, Y., F. Baron, and M. Gautier. 2003. Staphylococcus aureus and food poisoning. Genet. Mol. Res. 2:63-76.

Monecke, S., C. Luedicke, P. Slickers, and R. Ehricht. 2009. Molecular epidemiology of Staphylococcus aureus in asymptomatic carriers. Eur. J. Clin. Microbiol. Infect. Dis. 28:1159-1165.

Monecke, S., P. Slickers, and R. Ehricht. 2008. Assignment of Staphylococcus aureus isolates to clonal complexes based on microarray analysis and pattern recognition. FEMS Immunol. Med. Microbiol. 53:237-251.

Moser, A., R. Stephan, S. Corti, and S. Johler. 2013. Comparison of genomic and antimicrobial resistance features of latex agglutination test-positive and latex agglutination test-negative Staphylococcus aureus isolates causing bovine mastitis. J. Dairy Sci. 96:329-334.

Oliver, S. P., K. J. Boor, S. C. Murphy, and S. E. Murinda. 2009. Food safety hazards associated with consumption of raw milk. Foodborne Pathog. Dis. 6:793-806.

Ostyn, A., M. L. De Buyser, F. Guillier, J. Groult, B. Felix, S. Salah, G. Delmas, and J. A. Hennekinne. 2010. First evidence of a food poisoning outbreak due to staphylococcal enterotoxin type E, France, 2009. Euro Surveill. 15:19528.

Peng, S., W. Hoffmann, W. Bockelmann, J. Hummerjohann, R Stephan, and P. Hammer. 2013. Fate of Shiga toxin-producing and generic Escherichia coli during production and ripening of semihard raw milk cheese. J. Dairy Sci. 96:815-823.

Resch, G., P. François, D. Morisset, M. Stojanov, E. J. Bonetti, J. Schrenzel, O. Sakwinska, and P. Moreillon. 2013. Human-to-bovine jump of Staphylococcus aureus CC8 is associated with the loss of a $\beta$-hemolysin converting prophage and the acquisition of a new staphylococcal cassette chromosome. PLoS ONE 8:e58187.

Sakwinska, O., D. Morisset, J.-Y. Madec, A. Waldvogel, P. Moreillon, and M. Haenni. 2011. Link between genotype and antimicrobial resistance in bovine mastitis-related Staphylococcus aureus strains, determined by comparing Swiss and French isolates from the Rhône Valley. Appl. Environ. Microbiol. 77:3428-3432.

Scallan, E., R. M. Hoekstra, F. J. Angulo, R. V. Tauxe, M.-A. Widdowson, S. L. Roy, J. L. Jones, and P. M. Griffin. 2011. Foodborne illness acquired in the United States-Major pathogens. Emerg. Infect. Dis. 17:7-15.

Thomas, D. S. Chou, O. Dauwalder, and G. Lina. 2007. Diversity in Staphylococcus aureus enterotoxins. Chem. Immunol. Allergy 93:24-41.

Tranter, H. S. 1990. Foodborne staphylococcal illness. Lancet 336:1044-1046.

van Belkum, A., N. J. Verkaik, C. P. de Vogel, H. A. Boelens, J. Verveer, J. L. Nouwen, H. A. Verbrugh, and H. F. L. Wertheim. 2009. Reclassification of Staphylococcus aureus nasal carriage types. J. Infect. Dis. 199:1820-1826.

Wattinger, L., R. Stephan, F. Layer, and S. Johler. 2012. Comparison of Staphylococcus aureus isolates associated with food intoxication with isolates from human nasal carriers and human infections. Eur. J. Clin. Microbiol. Infect. Dis. 31:455-464.

Yabe, S., T. Takano, W. Higuchi, S. Mimura, Y. Kurosawa, and T. Yamamoto. 2010. Spread of the community-acquired methicillinresistant Staphylococcus aureus USA300 clone among family members in Japan. J. Infect. Chemother. 16:372-374. 